\title{
Article \\ Chili and Sweet Pepper Seed Oil Used as a Natural Antioxidant to Improve the Thermo-Oxidative Stability of Sunflower Oil
}

\author{
Ileana Cocan ${ }^{1,+}+\mathbb{D}$, Monica Negrea ${ }^{1, *}$, Antoanela Cozma ${ }^{2, *}$, Ersilia Alexa ${ }^{1,+} \mathbb{D}$, Mariana-Atena Poiana ${ }^{1}$, \\ Diana Raba ${ }^{3}$, Corina Danciu ${ }^{4}$, Iuliana Popescu ${ }^{2}$, Andreea I. Cadariu ${ }^{1}$, Diana Obistioiu ${ }^{5}$ iD and Isidora Radulov ${ }^{2}$
}

1 Faculty of Food Engineering, Banat's University of Agricultural Sciences and Veterinary Medicine "King Michael I of Romania" from Timisoara, Calea Aradului No. 119, 300645 Timisoara, Romania; ileanacocan@usab-tm.ro (I.C.); ersiliaalexa@usab-tm.ro (E.A.); marianapoiana@usab-tm.ro (M.-A.P.); andreeailas@yahoo.com (A.I.C.)

2 Faculty of Agriculture, Banat's University of Agricultural Sciences and Veterinary Medicine "King Michael I of Romania" from Timisoara, Calea Aradului No. 119, 300645 Timisoara, Romania; iulianapopescu@usab-tm.ro (I.P.); isidoraradulov@usab-tm.ro (I.R.)

3 Faculty of Management and Rural Tourism, Banat's University of Agricultural Sciences and Veterinary Medicine "King Michael I of Romania" from Timisoara, Calea Aradului No. 119, 300645 Timisoara, Romania; diana.raba@usab-tm.ro

4 Faculty of Pharmacy, University of Medicine and Pharmacy "Victor Babes" Timisoara, Eftimie Murgu Square No. 2, 300041 Timisoara, Romania; corina.danciu@umft.ro

5 Faculty of Veterinary Medicine, Banat's University of Agricultural Sciences and Veterinary Medicine "King Michael I of Romania" from Timisoara, Calea Aradului No. 119, 300645 Timisoara, Romania; dianaobistioiu@usab-tm.ro

updates

Citation: Cocan, I.; Negrea, M.; Cozma, A.; Alexa, E.; Poiana, M.-A.; Raba, D.; Danciu, C.; Popescu, I.; Cadariu, A.I.; Obistioiu, D.; et al. Chili and Sweet Pepper Seed Oil Used as a Natural Antioxidant to Improve the Thermo-Oxidative Stability of Sunflower Oil. Agronomy 2021, 11, 2579. https://doi.org/ 10.3390/agronomy11122579

Academic Editor: Aritz Royo-Esnal

Received: 30 November 2021 Accepted: 17 December 2021 Published: 18 December 2021

Publisher's Note: MDPI stays neutral with regard to jurisdictional claims in published maps and institutional affiliations.

Copyright: (c) 2021 by the authors. Licensee MDPI, Basel, Switzerland. This article is an open access article distributed under the terms and conditions of the Creative Commons Attribution (CC BY) license (https:// creativecommons.org/licenses/by/ $4.0 /)$.
* Correspondence: monicanegrea@usab-tm.ro (M.N.); cozma@usab-tm.ro (A.C.)

+ The two authors contributed equally to the work.

Abstract: The main purpose of this work was to assess the potential of chili pepper seed oil (CPSO) and sweet pepper seed oil (SPSO) to inhibit or retard the thermo-oxidative processes undergoing in sunflower oil (SFO) when subjected to high-temperature heating for 4 and $8 \mathrm{~h}$ in simulated frying conditions. The effects of high-temperature treatment for 4 and $8 \mathrm{~h}$ on the fatty acid composition and the lipid oxidation degree of the investigated oil samples were evaluated using the peroxide value $(\mathrm{PV})$, the $p$-anisidine value ( $p$-AV) and the thiobarbituric acid test (TBA). All determinations were performed before and after sample heating in order to evaluate the changes in lipid oxidation as well as in the chemical composition. In all studied samples, both after $4 \mathrm{~h}$ and $8 \mathrm{~h}$ of high-temperature heating, there was an increase of the saturated fatty acid content. This increase is lower in the case of SFO samples supplemented with CPSO and SPSO when compared with SFO. A $41.67 \%$ increase was recorded for the SFO sample supplemented with $300 \mathrm{ppm} \mathrm{CPSO}$, and a $36.76 \%$ increase was recorded for the SFO supplemented with 300 ppm SPSO, compared to the $44.97 \%$ increase recorded for the SFO. Heating the samples supplemented with CPSO and SPSO with a concentration of 300 ppm for $8 \mathrm{~h}$ led to the much lower values of the investigated parameters in relation to the control sample, as follows: PV $(12.95 \pm 0.17 \mathrm{meq} / \mathrm{kg}$ oil for SFO $+300 \mathrm{ppm} \mathrm{CPSO}$ and $13.45 \pm 0.32 \mathrm{meq} / \mathrm{kg}$ oil for $\mathrm{SFO}+300$ ppm SPSO, compared with $16.4+0.17 \mathrm{meq} / \mathrm{kg}$ oil for SFO), $p$-AV $(63.445 \pm 1.259 \mathrm{ppm}$ oil for SFO + 300 ppm CPSO and $64.122 \pm 1.208$ ppm oil for SFO + 300 ppm SPSO, compared with $72.493+1.340$ ppm oil for SFO), CD (45\%; 30\%), TOTOX (88.374 for SFO + 300 ppm CPSO and 101.366 for SFO + 300 ppm SPSO compared with $105.347 \mathrm{ppm}$ for SFO) and TBA (98.92 $\pm 2.49 \mu \mathrm{g}$ $\mathrm{MDA} / \mathrm{g}$ oil for SFO + $300 \mathrm{ppm} \mathrm{CPSO}$ and $114.24 \pm 3.51 \mu \mathrm{g} \mathrm{MDA} / \mathrm{g}$ oil for SFO + $300 \mathrm{ppm} \mathrm{SPSO}$, compared with $180.08+5.82 \mu \mathrm{g}$ MDA/g oil for SFO). Regarding the lipid oxidation process occurring during the heat treatment, we observed the reduction of lipid oxidation by the addition of CPSO and SPSO and recommend these seed oils as potential natural antioxidants in order to improve the oxidative stability of SFO during heat treatment.

Keywords: sweet pepper seed oil; chili pepper seed oil; thermo-oxidative stability; sunflower oil 


\section{Introduction}

Food lipids are components subjected to heat treatment at medium and high temperatures, which, in the presence of oxygen, suffer from various processes such as thermooxidation, polymerization and hydrolysis. These processes lead to the decomposition of the chemical composition, producing an unpleasant odor and decreasing the nutritional value of the fried product [1].

Oxidation processes are one of the main damage sources that occur during the processing, storage, distribution and final processing of food products. Lipid oxidation products are ubiquitous in food, but the problem of lipid oxidation severely compromises the quality of some foods and limits the shelf life of others [2].

The oxidation degree (rancidity) of edible vegetable oils is an indicator of their freshness, with major implications for food quality and safety [3].Vegetable oils are preferred for consumption due to their low cholesterol level, but they are more exposed to oxidation due to the high level of unsaturated fatty acids compared to animal lipids, which contain saturated fatty acids and therefore do not react with other chemicals, especially oxygen [4]. Recently, new natural preservative discoveries that provide better thermal stability of edible oils during frying were discussed [5]. The addition of synthetic antioxidants to increase the oxidative stability of edible oils is not recommended [6]; however, lately there has been growing interest in identifying natural sources of antioxidants [7-9], with a particular emphasis on byproducts [1]. Recent studies have pointed out that, due their toxicity and carcinogenic effects in animals and humans, the use of synthetic antioxidants is restricted [10]. Currently, the US Food and Drug Administration (FDA) and the European Food Safety Authority (EFSA) have established legal limits with regard to the allowed amounts of synthetic antioxidants [11].

Sunflower oil (SFO) is one of the main edible vegetable oils, with high levels of polyunsaturated fatty acids, especially linoleic acid. It is added to various food products, contributing to the increase of the essential fatty acid content in their composition [12].

The sweet pepper and chili seeds are a cheap raw material and a source of fat with high value oils due to their high antioxidant content. The processing of peppers in the canning industry results in a significant amount of seeds, whose recovery is currently limited. Pepper seed oil has a high content of linoleic acid, about $70 \%$, and is rich in vitamin $\mathrm{C}$ and capsaicin, which is the main active component of hot peppers, thereby generating an antioxidant effect [12,13]. The antioxidant mechanism of capsaicin has been reported by Kogure et al. [14], which showed that capsaicin delayed the lipid oxidation of soybean oil during the frying process at $200^{\circ} \mathrm{C}$ [15] and $140{ }^{\circ} \mathrm{C}$ [5] but is not so effective at $100{ }^{\circ} \mathrm{C}$ [16] However, data regarding the antioxidant effect of pepper seed oil in the case of sunflower oil have not been reported in the literature.

Given that lately there is an increasing emphasis regarding the concept of circular economy and promoting the sustainability of alternative resources, capitalizing on byproducts resulting from vegetable processing is a topical approach with a positive economic, social and environmental impact. In this context, the aim of this study was to determine the fatty acid content as well as the antioxidant effect of the oil obtained from pepper seeds, and the potential uses as a sustainable food matrix.

In this paper, we evaluated the potential of chili pepper seed oil (CPSO) and sweet pepper seed oil (SPSO) as a source of natural antioxidants that could increase the shelf life of SFO. Primarily, we evaluated the changes in fatty acids in the sample composition concerning the degree of oxidation of the lipids. Moreover, the peroxide value (PV), the $p$-anisidine value $(p-\mathrm{AV})$ and the thiobarbituric acid test (TBA) analysis were determined. The total oxidation value (TOTOX) was calculated using the PV and $p$-AV values. The antioxidative activity of CPSO and SPSO in the sunflower oil was evaluated during, before and after thermal treatment, and was compared with the antioxidative activity of the commercially available antioxidant BHT. 


\section{Materials and Methods}

\subsection{Oil Samples}

SFO, CPSO and SPSO were purchased from the Solaris, Bucharest, Romania, who produces cold-pressed vegetal oils, natural, $100 \%$, without the addition of any additives. The reagents used were of analytical grade and were purchased from Sigma-Aldrich Chemie GmbH, München, Germany.

\subsection{Application of CPSO and SPSO to SFO}

A total of 8 samples were weighed in $50 \mathrm{~mL}$ of SFO oil free of synthetic antioxidants. In one, 200 ppm of BHT (maximum legal admissible dose) was added; in six were added CPSO and SPSO at three levels of concentrations (100 ppm, 200 ppm and 300 ppm). Moreover, a SFO sample without any antioxidant was used as a control. The obtained oil mixtures were stirred using a mechanical stirrer for complete homogenization.

\subsection{Heating Processes}

To examine the heating effect on the sunflower oil supplemented with CPSO, SPSO and BHT, the individual samples were subjected to the heat treatment in a conventional furnace (Esmach, Esmach Ali Group S.r.l., Grisignano, Italy; 1200 W, $50 \mathrm{~Hz}$ ) to a temperature of $180{ }^{\circ} \mathrm{C}$, similar to the conditions specific to the food industry, for $8 \mathrm{~h}$ of frying. After each heating period, the samples were removed from the furnace, cooled and analyzed.

The experimental process of heating was developed in agreement with previous studies [1,3]. Preliminary tests have been carried out to establish the heat regime for this treatment. The samples were heated separately for 4 to $8 \mathrm{~h}$.

The studied oil sample temperature was determined immediately after each heating period with the help of a calibrated chromel-alumel thermocouple (HI 935009, Hanna Instruments, New York, NY, USA). The internal temperatures of the oil sample heated in a conventional oven are shown in Table 1.

Table 1. Temperature evolution for sunflower oil samples during heating.

\begin{tabular}{cccc}
\hline & \multicolumn{3}{c}{ Time } \\
\cline { 2 - 4 } Temperature $\left({ }^{\circ} \mathrm{C}\right)$ & $0 \mathrm{~h}$ & $4 \mathrm{~h}$ & $8 \mathrm{~h}$ \\
& 26.4 & 177.4 & 179.1 \\
\hline
\end{tabular}

The samples were removed from the oven, cooled rapidly and stored at $-18{ }^{\circ} \mathrm{C}$ until they were analyzed. Separate samples were used for each heating period.

\subsection{Determination of Fatty Acid Composition by GC-MS}

Fatty acids were analyzed as fatty acid methyl esters (FAME). The fatty acids contained in $0.1 \mathrm{~g}$ lipids were derivatized with $3 \mathrm{~mL}$ of $3 \%$ boron trifluoride $20 \%$ (Sigma-Aldrich Chemie $\mathrm{GmbH}$, München, Germany). The derivatization was performed for $1 \mathrm{~h}$ at $80^{\circ} \mathrm{C}$ in an ultrasonic bath (FALC Instruments, Treviglio, Italy). After cooling, $2.5 \mathrm{~mL}$ of 10\% $\mathrm{NaCl}$ solution was added, and FAME was extracted in $2 \mathrm{~mL}$ of hexane (Sigma-Aldrich Chemie $\mathrm{GmbH}$, München, Germany). The organic layer was separated by centrifugation at $3000 \mathrm{rpm}$ for $15 \mathrm{~min}$ (Centrifuge Hermle Labortechnik, Wehingen, Germany). The FAMEs were analyzed using Shimadzu GCMS-QP2010PLUS (Kyoto, Japan) equipment with ATWAX column $(30 \mathrm{~m}, 0.32 \mathrm{~mm}$ i.d., $1 \mu \mathrm{m})$. The temperature program was $140{ }^{\circ} \mathrm{C}$ for $10 \mathrm{~min}$, then the temperature was raised by $7^{\circ} \mathrm{C} / \mathrm{min}$ up to $250{ }^{\circ} \mathrm{C}$, with this temperature being maintained for $10 \mathrm{~min}$. The partition ratio was $1: 10$. The injection port temperature was set at $250{ }^{\circ} \mathrm{C}$, the source temperature was $210^{\circ} \mathrm{C}$ and ionic interface temperature was $255^{\circ} \mathrm{C}$. For FAME determination, hexane was used as a solvent, and helium was used as a carrier gas, with a flow rate of $1.00 \mathrm{~mL} / \mathrm{min}$ and a linear velocity of $37.8 \mathrm{~cm} / \mathrm{s}$. FAME peaks were identified using NIST05 library and quantified by area normalization method. The percentage of compounds was determined by reporting the peak area corresponding to a specific compound to the total peak area (for all identified components) [17]. 
Saturated fatty acids (SFA) were calculated based on the sum of C16:0 and C18:0, monounsaturated fatty acids (MUFA) were calculated as sum of C18:1 and C22:1 and polyunsaturated fatty acids (PUFA) were represented by C18:2.

In this section, the decreases/increases registered for SFA, MUFA and PUFA after 4 and $8 \mathrm{~h}$ of heat treatment were also calculated, these being expressed as a percentage.

\subsection{Determination of Peroxide Value}

The peroxide (PV) value was determined by the iodometric method according to the standard method for oil analysis, and the results were expressed in meq $/ \mathrm{kg}$ oil [18].

\section{6. $p$-Anisidine Value ( $p$-AV)}

To determine the $p-\mathrm{AV}$, a spectrophotometric analysis method was used by measuring the absorbance at $350 \mathrm{~nm}$, according to the official method (AOCS Official Method Cd 18-90), [19]. For the $p$-AV measurement, $2 \mathrm{~g}$ of oil sample was dissolved in $25 \mathrm{~mL}$ of isooctane (Sigma-Aldrich Chemie GmbH, München, Germany). The absorbance of the obtained solutions was measured against a blank isooctane sample at $350 \mathrm{~nm}$ using a double-beam UV-Vis spectrophotometer (Specord 205; Analytik Jena AG, Jena, Germany). A total of $5 \mathrm{~mL}$ of the obtained solutions were transferred to individual tubes, as well as $5 \mathrm{~mL}$ of the isooctane solvent used as a control and $1 \mathrm{~mL}$ of the p-anisidine/glacial acetic acid solution $(0.25 \%, w / v)$ (Sigma-Aldrich Chemie $\mathrm{GmbH}$, München, Germany) was added. After $10 \mathrm{~min}$, the absorbance of the oil solutions in the tubes was measured at $350 \mathrm{~nm}$ compared to the solution containing isooctane and p-anisidine. The $p$-AV was calculated based on the relationship shown in Equation (1):

$$
p-\mathrm{AV}=25 \times \frac{1.2 \times \mathrm{A}_{2}-\mathrm{A}_{1}}{\mathrm{~W}}
$$

where $\mathrm{A}_{1}$-the absorbance of $2 \mathrm{~g}$ oil sample in $25 \mathrm{~mL}$ isooctane measured against a blank of isooctane; $\mathrm{A}_{2}$-the absorbance of $2 \mathrm{~g}$ oil sample in $25 \mathrm{~mL}$ isooctane with $1 \mathrm{~mL} p$-anisidine solution measured against a sample of isooctane containing $p$-anisidine solution; $\mathrm{W}$-the sunflower oil sample weight $(\mathrm{g})$.

\subsection{Total Oxidation Value (TOTOX)}

$\mathrm{PV}$ and $p-\mathrm{AV}$ were converted to the total oxidation value (TOTOX) by using Equation (2).

$$
\text { Totox value }=2 \cdot \mathrm{PV}+\mathrm{AV}
$$

\subsection{Assessing the Lipid Oxidation Degree of Oil Samples by TBA Test}

This method represents one of the most commonly used methods to evaluate the lipid oxidation degree of oil samples and is based on measuring the absorbance of the TBAmalonaldehyde complex at 532-535 nm [2]. Malondialdehyde (MDA) is a three-carbon dialdehyde, being one of the oxidation products of the unsaturated acid intermediates. Literature data has shown that malondialdehyde can be dosed by a treatment with thiobarbituric acid, the reaction of which forms red condensation products that absorb at $532-535 \mathrm{~nm}$ with a molar absorptivity of 27.5 absorbance units/ $\mathrm{mmol}$ [20].

Determination of antioxidant activity by the thiobarbituric acid method (TBA) was performed according to the method of Singh et al. [21], Kikuzaki and Nakatani [22] and Tarladgis et al. [23], with small changes. The TBA was expressed as $\mu \mathrm{g}$ of malonaldehyde per g sample.

A total of $2 \mathrm{~g}$ of oil of each type was weighed, to which $5 \mathrm{~mL}$ of benzene and $4 \mathrm{~mL}$ of thiobarbituric acid ( $0.67 \%$ aqueous solution) (Sigma-Aldrich Chemie $\mathrm{GmbH}$, München, Germany) were added. The samples prepared were shaken for $30 \mathrm{~min}$ using a mechanical stirrer (Heidolph, Illinois, IL, USA) and maintained at rest for $10 \mathrm{~min}$ to separate the phases. The supernatant was taken into the tubes and then heated on the water bath at $80^{\circ} \mathrm{C}$ for $45 \mathrm{~min}$. 
After cooling, absorbance of the supernatant was measured at $540 \mathrm{~nm}$ using the Specord 210 Analytik Jena spectrophotometer against an oil-free control sample. The calibration curve of the thiobarbituric acid test was performed by measuring the extinctions of some samples with known concentrations of malonaldehyde. The amount of malonaldehyde in the samples was calculated based on the calibration line, depending on the extinctions read and the sample weight taken into work.

\subsection{Statistical Analysis}

All determinations were carried out in triplicates and values were presented as mean values \pm SD. Values $p<0.05$ were considered statistically significant. One-way ANOVA and two-sample $t$-test assuming equal variances were applied to evaluate the statistical significance. Statistical processing data was performed using Microsoft Excel 2010.

\section{Results}

\subsection{Fatty Acids Composition}

The effects of the high-temperature treatment for 4 and $8 \mathrm{~h}$ on the fatty acid composition of the investigated oil samples are shown in Table $2(p<0.05)$.

Table 2. The effect of heat treatment for 4 and $8 \mathrm{~h}$ on fatty acid composition of oil samples.

\begin{tabular}{|c|c|c|c|c|c|}
\hline \multirow{3}{*}{ Sample } & \multicolumn{5}{|c|}{ Fatty Acids (\%) } \\
\hline & C16:0 & C18:0 & C18:1 & C18:2 & C22:1 \\
\hline & \multicolumn{5}{|c|}{ initial } \\
\hline SFO & $8.54 \pm 0.13^{a}$ & $3.33 \pm 0.10^{a}$ & $30.76 \pm 1.22^{\mathrm{a}}$ & $56.91 \pm 1.11^{\mathrm{a}}$ & nd \\
\hline $\mathrm{SFO}+\mathrm{BHT}$ & $8.51 \pm 0.16^{\mathrm{a}}$ & $3.53 \pm 0.09^{a, c}$ & $30.63 \pm 1.00^{\mathrm{a}}$ & $56.83 \pm 1.39^{a}$ & nd \\
\hline CPSO & $13.90 \pm 0.45^{b}$ & $4.26 \pm 0.12^{b}$ & $11.42 \pm 0.29^{b}$ & $70.41 \pm 2.04^{b}$ & nd \\
\hline SPSO & $13.10 \pm 0.47^{\mathrm{b}}$ & $4.82 \pm 0.19^{\mathrm{d}}$ & $12.51 \pm 0.30^{c}$ & $69.39 \pm 2.05^{b}$ & $0.18 \pm 0.03^{\mathrm{a}}$ \\
\hline $\mathrm{SFO}+100$ ppmCPSO & $9.08 \pm 0.17^{c}$ & $3.44 \pm 0.11^{\mathrm{a}}$ & $28.84 \pm 0.97^{\mathrm{a}, \mathrm{e}}$ & $58.28 \pm 1.46^{\mathrm{a}, \mathrm{c}}$ & nd \\
\hline SFO + 200 ppmCPSO & $9.69 \pm 0.20^{d}$ & $3.52 \pm 0.10^{a, c, f}$ & $26.90 \pm 0.92^{\mathrm{d}, \mathrm{e}}$ & $59.66 \pm 1.88^{a, c}$ & nd \\
\hline $\mathrm{SFO}+300$ ppmCPSO & $10.18 \pm 0.24^{\mathrm{d}, \mathrm{e}}$ & $3.62 \pm 0.12^{\mathrm{c}, \mathrm{f}}$ & $24.82 \pm 0.89^{\mathrm{d}, \mathrm{f}}$ & $60.98 \pm 1.28^{c}$ & nd \\
\hline SFO + 100 ppmSPSO & $8.98 \pm 0.16^{c}$ & $3.49 \pm 0.09^{\mathrm{a}, \mathrm{f}}$ & $28.96 \pm 0.96^{\mathrm{a}, \mathrm{e}}$ & $58.19 \pm 1.40^{\mathrm{a}, \mathrm{c}}$ & $0.02 \pm 0.01^{b}$ \\
\hline SFO + 200 ppmSPSO & $9.50 \pm 0.18^{\mathrm{d}, \mathrm{f}}$ & $3.63 \pm 0.16^{\mathrm{c}, \mathrm{f}}$ & $27.12 \pm 0.77^{\mathrm{d}, \mathrm{e}, \mathrm{g}}$ & $59.39 \pm 1.84^{\mathrm{a}, \mathrm{c}}$ & $0.05 \pm 0.02^{b, d}$ \\
\hline SFO + 300 ppmSPSO & $9.89 \pm 0.17^{\mathrm{d}, \mathrm{f}}$ & $3.75 \pm 015^{\mathrm{e}, \mathrm{f}}$ & $25.37 \pm 0.93^{\mathrm{d}}$ & $60.62 \pm 1.81^{c}$ & $0.07 \pm 001^{\mathrm{c}, \mathrm{d}}$ \\
\hline Sample & \multicolumn{5}{|c|}{$4 \mathrm{~h}$} \\
\hline SFO & $8.21 \pm 0.21^{a}$ & $8.99 \pm 0.28^{a}$ & $33.67 \pm 1.08^{a}$ & $49.12 \pm 1.04^{a}$ & nd \\
\hline $\mathrm{SFO}+\mathrm{BHT}$ & $8.40 \pm 0.16^{\mathrm{a}}$ & $5.15 \pm 0.12^{b}$ & $31.56 \pm 1.06^{\mathrm{a}, \mathrm{d}}$ & $54.89 \pm 1.09^{b}$ & nd \\
\hline CPSO & $12.54 \pm 0.51^{\mathrm{b}}$ & $8.21 \pm 0.20^{c}$ & $10.85 \pm 0.40^{b}$ & $68.40 \pm 1.88^{c}$ & nd \\
\hline SPSO & $12.47 \pm 0.37^{b}$ & $9.49 \pm 0.24^{\mathrm{a}, \mathrm{d}}$ & $10.14 \pm 0.26^{b}$ & $67.43 \pm 2.13^{c}$ & $0.41 \pm 0.03^{\mathrm{a}}$ \\
\hline SFO + 100 ppmCPSO & $8.64 \pm 0.34^{\mathrm{a}, \mathrm{d}}$ & $8.94 \pm 0.22^{\mathrm{a}, \mathrm{e}}$ & $31.28 \pm 0.96^{\mathrm{c}, \mathrm{d}}$ & $51.05 \pm 0.95^{\mathrm{a}, \mathrm{d}}$ & nd \\
\hline $\mathrm{SFO}+200$ ppmCPSO & $9.07 \pm 0.25^{\mathrm{c}, \mathrm{d}}$ & $8.85 \pm 0.15^{\mathrm{a}, \mathrm{e}}$ & $29.11 \pm 0.97^{\mathrm{c}, \mathrm{f}}$ & $52.95 \pm 1.07^{\mathrm{b}, \mathrm{d}}$ & nd \\
\hline $\mathrm{SFO}+300$ ppmCPSO & $9.50 \pm 0.35^{c}$ & $8.75 \pm 0.22^{\mathrm{a}, \mathrm{e}}$ & $26.85 \pm 0.99^{e}$ & $54.89 \pm 1.33^{b}$ & nd \\
\hline SFO + 100 ppmSPSO & $8.61 \pm 0.22^{a}$ & $9.04 \pm 0.24^{\mathrm{a}}$ & $31.38 \pm 1.06^{\mathrm{a}, \mathrm{d}, \mathrm{f}}$ & $50.93 \pm 1.09^{\mathrm{a}, \mathrm{d}}$ & $0.03 \pm 0.01^{b}$ \\
\hline $\mathrm{SFO}+200$ ppmSPSO & $9.09 \pm 0.20^{\mathrm{c}, \mathrm{d}}$ & $9.08 \pm 0.23^{\mathrm{a}}$ & $28.99 \pm 1.02 e^{\mathrm{e}, \mathrm{f}}$ & $52.78 \pm 1.04^{\mathrm{b}, \mathrm{d}}$ & $0.06 \pm 0.02^{b, c}$ \\
\hline $\mathrm{SFO}+300$ ppmSPSO & $9.54 \pm 0.19^{c}$ & $9.16 \pm 0.17^{\mathrm{a}}$ & $26.59 \pm 0.92^{\mathrm{e}}$ & $54.64 \pm 1.44^{\mathrm{b}}$ & $0.11 \pm 0.03^{c}$ \\
\hline Sample & \multicolumn{5}{|c|}{$8 \mathrm{~h}$} \\
\hline SFO & $8.80 \pm 0.23^{a}$ & $9.83 \pm 0.29^{a}$ & $32.81 \pm 0.96^{\mathrm{a}}$ & $47.56 \pm 1.13^{\mathrm{a}}$ & nd \\
\hline $\mathrm{SFO}+\mathrm{BHT}$ & $8.89 \pm 0.38^{a, c}$ & $6.50 \pm 0.15^{b}$ & $32.32 \pm 1.10^{\mathrm{a}, \mathrm{d}}$ & $53.89 \pm 1.15^{b}$ & nd \\
\hline CPSO & $11.81 \pm 0.41^{\mathrm{b}}$ & $10.49 \pm 0.35^{\mathrm{a}}$ & $10.40 \pm 0.44^{b}$ & $67.12 \pm 1.60^{\mathrm{c}}$ & nd \\
\hline SPSO & $12.24 \pm 0.46^{b}$ & $9.96 \pm 0.25^{\mathrm{a}}$ & $10.51 \pm 0.26^{b}$ & $66.58 \pm 1.38^{c}$ & $0.63 \pm 0.12^{\mathrm{a}}$ \\
\hline $\mathrm{SFO}+100$ ppmCPSO & $9.10 \pm 0.19^{c}$ & $9.89 \pm 0.32^{\mathrm{a}}$ & $30.70 \pm 0.98^{\mathrm{a}, \mathrm{d}}$ & $49.63 \pm 1.05^{\mathrm{d}, \mathrm{e}}$ & nd \\
\hline $\mathrm{SFO}+200$ ppmCPSO & $9.39 \pm 0.39^{c, e}$ & $9.97 \pm 0.27^{\mathrm{a}}$ & $28.37 \pm 1.03^{c}$ & $51.49 \pm 1.32^{\mathrm{b}, \mathrm{e}, \mathrm{f}}$ & nd \\
\hline $\mathrm{SFO}+300$ ppmCPSO & $9.72 \pm 0.37^{c, e}$ & $10.03 \pm 0.30^{a}$ & $26.08 \pm 0.98^{e}$ & $53.40 \pm 1.15^{b}$ & nd \\
\hline SFO + 100 ppmSPSO & $9.17 \pm 0.29^{c}$ & $9.85 \pm 0.34^{\mathrm{a}}$ & $30.59 \pm 0.61^{c, d, f f}$ & $49.46 \pm 1.23^{\mathrm{d}, \mathrm{f}, \mathrm{g}}$ & $0.04 \pm 0.01^{b}$ \\
\hline SFO + 200 ppmSPSO & $9.87 \pm 0.26^{\mathrm{d}, \mathrm{e}}$ & $9.86 \pm 0.31^{a}$ & $28.34 \pm 1.00^{\mathrm{c}, \mathrm{g}}$ & $51.38 \pm 1.25^{\mathrm{b}, \mathrm{e}, \mathrm{g}}$ & $0.09 \pm 0.01^{\mathrm{c}}$ \\
\hline $\mathrm{SFO}+300$ ppmSPSO & $9.83 \pm 0.38^{\mathrm{d}, \mathrm{e}}$ & $9.88 \pm 0.21^{\mathrm{a}}$ & $26.17 \pm 0.68^{\mathrm{e}}$ & $53.24 \pm 1.30^{b}$ & $0.18 \pm 0.04^{\mathrm{d}}$ \\
\hline
\end{tabular}

The values are expressed as mean values \pm standard deviations of all measurements. ${ }^{a-g}$ A $t$-test was used to compare the mean differences registered among samples; data within the same column sharing different superscripts are significantly different $(p<0.05)$; data within the same column sharing the same superscripts are not significantly different $(p>0.05)$. 
In the untreated oil samples, polyunsaturated fatty acids (PUFA) represented the largest amounts of identified fatty acids, namely linoleic acid (C18:2) followed by monounsaturated (MUFA), respectively, oleic acid (C18:1) and erucic acid (C22:1), identified only in SPSO and the samples containing SPSO. Saturated fatty acids (SFA) such as palmitic acid (C16:0) and stearic acid (C18:0) were identified in smaller quantities $(p<0.05)$.

Regarding the variation of the fatty acid content in the oil samples before thermal treatment, the results are as follows:

- The highest content of palmitic acid (C16:0) was found in CPSO (13.90\%) and the lowest in SFO + BHT (8.51\%);

- The highest content of stearic acid was found in SPSO (4.82\%) and the lowest in SFO (3.33\%);

- The highest content of oleic acid was identified in SFO (30.76\%) and the lowest in CPSO (11.42\%);

- The largest amounts of linoleic acid were registered in CPSO (70.41\%) and the smallest in SFO + BHT (56.83\%).

Erucic acid was identified in small quantities only in SPSO and the samples containing SPSO. For all the samples studied, after the heat treatment application, both at 4 and at $8 \mathrm{~h}$, there was a significant decrease in the proportion of PUFA (Table 3) due to the oxidation reaction produced during the heating process, this decrease being inversely proportional to the duration of the thermal process.

Table 3. The changes in fatty acid profiles of the oil samples in response to heating treatment.

\begin{tabular}{|c|c|c|c|c|c|c|c|c|c|c|}
\hline $\begin{array}{c}\text { Fatty } \\
\text { Acids (\%) }\end{array}$ & $\begin{array}{c}\text { SFO } \\
\text { (Control) }\end{array}$ & $\begin{array}{c}\text { SFO + } \\
\text { BHT }\end{array}$ & CPSO & SPSO & $\begin{array}{c}\text { SFO + } \\
100 \text { ppm } \\
\text { CPSO }\end{array}$ & $\begin{array}{c}\text { SFO + } \\
200 \text { ppm } \\
\text { CPSO }\end{array}$ & $\begin{array}{c}\text { SFO + } \\
300 \text { ppm } \\
\text { CPSO }\end{array}$ & $\begin{array}{c}\text { SFO + } \\
100 \text { ppm } \\
\text { SPSO }\end{array}$ & $\begin{array}{c}\text { SFO + } \\
200 \text { ppm } \\
\text { SPSO }\end{array}$ & $\begin{array}{c}\text { SFO + } \\
300 \text { ppm } \\
\text { SPSO }\end{array}$ \\
\hline & \multicolumn{10}{|c|}{ initial } \\
\hline SAT & 11.87 & 12.03 & 18.16 & 17.92 & 12.52 & 13.20 & 13.80 & 12.46 & 13.13 & 13.64 \\
\hline MUFA & 30.76 & 30.63 & 11.42 & 12.69 & 28.84 & 26.90 & 24.82 & 28.98 & 27.17 & 25.44 \\
\hline PUFA & 56.91 & 56.83 & 70.41 & 69.39 & 58.28 & 59.66 & 60.98 & 58.19 & 59.39 & 60.62 \\
\hline & \multicolumn{10}{|c|}{$4 \mathrm{~h}$} \\
\hline SAT & 17.20 & 13.54 & 20.75 & 21.96 & 17.57 & 17.94 & 18.25 & 17.66 & 18.17 & 18.65 \\
\hline MUFA & 33.67 & 31.56 & 10.85 & 10.56 & 31.28 & 29.11 & 26.85 & 31.41 & 29.05 & 26.70 \\
\hline PUFA & 49.12 & 54.89 & 68.40 & 67.43 & 51.05 & 52.95 & 54.89 & 50.93 & 52.78 & 54.64 \\
\hline & \multicolumn{10}{|c|}{$8 \mathrm{~h}$} \\
\hline SAT & 18.63 & 15.40 & 22.30 & 22.20 & 18.98 & 19.36 & 19.76 & 19.02 & 19.73 & 19.70 \\
\hline MUFA & 32.81 & 32.32 & 10.40 & 11.14 & 30.70 & 28.37 & 26.08 & 30.63 & 28.43 & 26.35 \\
\hline PUFA & 47.56 & 53.89 & 67.12 & 66.58 & 49.63 & 51.50 & 53.40 & 49.46 & 51.38 & 53.24 \\
\hline
\end{tabular}

In the case of samples supplemented with CPSO and SPSO after $4 \mathrm{~h}$ of heat treatment, the lowest decrease in PUFA (\%) was recorded for SFO + 300 ppm CPSO $(9.99 \%)$ and SFA +300 ppm SPSO (9.87\%). The decrease of PUFA (\%) in the SFO control sample was $13.69 \%$ compared to SFO + BHT, which decreased with $3.41 \%$ (Figure 1). Within $4-8 \mathrm{~h}$ of the heat treatment, a slowdown in the oxidation process was recorded, with a smaller decrease in the proportion of PUFA (\%). However, the lowest decrease in PUFA (\%) compared to the 4-h values was found in the case of SFO $+300 \mathrm{ppm} \mathrm{CPSO}(2.71 \%)$ and SFA + $300 \mathrm{ppm}$ SPSO $(2.55 \%)$, compared to the SFO control sample that recorded a decrease of $3.18 \%$ and $\mathrm{SFO}+\mathrm{BHT}$, which recorded a decrease of $1.82 \%$.

In all the samples studied, both after $4 \mathrm{~h}$ and after $8 \mathrm{~h}$ of heat treatment, there was an increase in the content of saturated fatty acids (SFA), this increase being directly proportional to the duration of the heat treatment. The highest increase was registered for $\mathrm{SFO}+100 \mathrm{ppm} \mathrm{CPSO} \mathrm{(41.16 \% )} \mathrm{and} \mathrm{SFO} \mathrm{+} 100 \mathrm{ppm} \mathrm{SPSO}(41.73 \%)$, compared to the SFO control sample which registered an increase of $44.90 \%$ and the SFO + BHT test with an increase of $12.55 \%$ (Figure 1). PUFA growth was slower in the $4-8 \mathrm{~h}$ heat treatment period than in the first $4 \mathrm{~h}$ (Figure 1). 


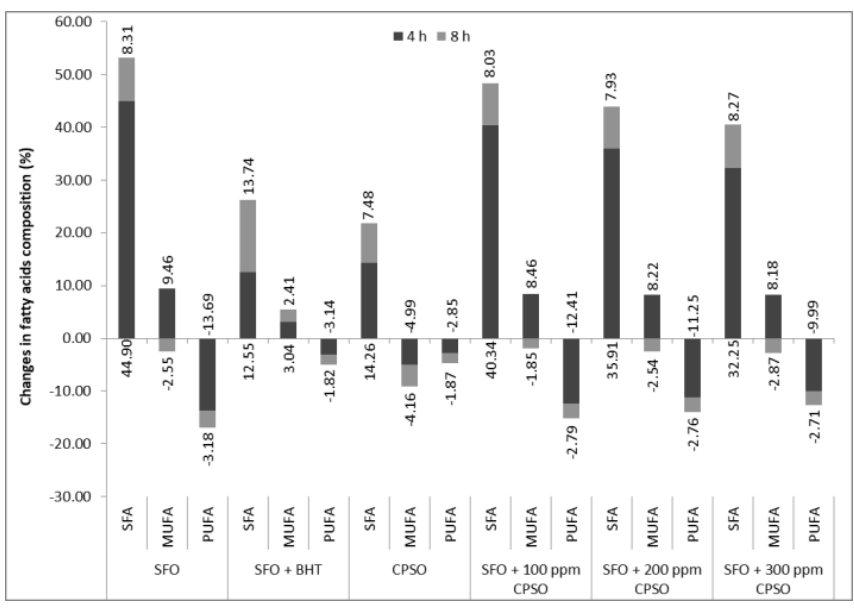

(a)

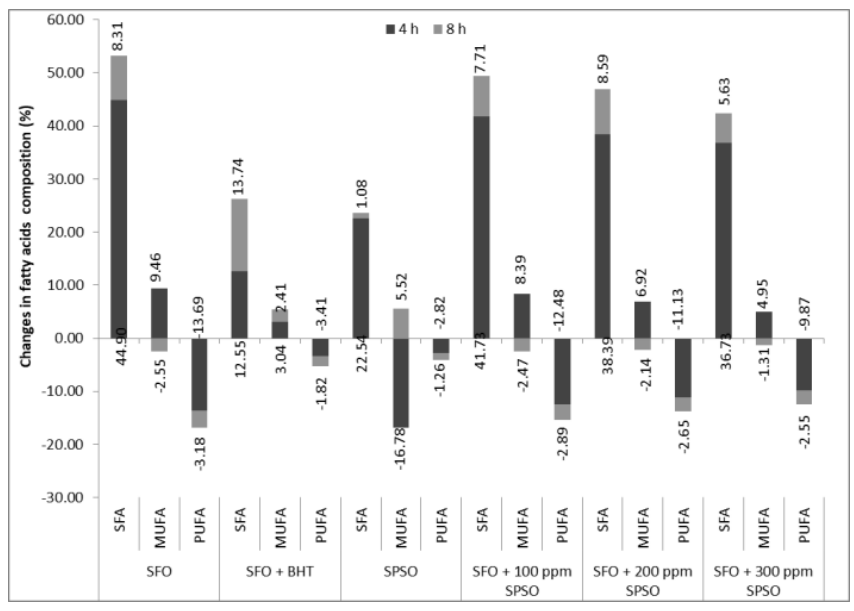

(b)

Figure 1. Changes in fatty acid composition of oil samples in response to heat treatment versus SFO sample. (a) CPSO; (b) SPSO.

It is worth mentioning that the ratio of saturated and polyunsaturated fatty acids increased proportionally with the concentration of CPSO and SPSO, and the MUFA ratio decreased inversely proportional with the concentrations of CPSO and SPSO used.

\subsection{Peroxide Value}

The data presented in Table 4 express the PV changes recorded during heating in response to the addition of BHT, CPSO and SPSO to the oil. The peroxide value was in the range of $1.29-15.66 \mathrm{meq} / \mathrm{kg}$ for the oil samples with additions of CPSO and SPSO, while for the control sample (SFO) values were determined between $1.58-16.40 \mathrm{meq} / \mathrm{kg}$, and between 1.59-12.37 meq/ $\mathrm{kg}$ for SFO + BHT. Both after $4 \mathrm{~h}$ and after $8 \mathrm{~h}$ of heat treatment, the highest PV was observed for the control sample (SFO) followed by SFO + $100 \mathrm{ppm}$ SPSO, SFO + 100 ppm CPSO, SFO + 200 ppm SPSO, SFO + 200 ppm CPSO, SFO + 300 ppm SPSO, SFO + 300 ppm CPSO and SFO-BHT, respectively. The CPSO and SPSO samples recorded the lowest $\mathrm{PV}$ values both before and after the heat treatment.

After $8 \mathrm{~h}$ of heat treatment, there was a regular pattern of PV growth for all samples. The values recorded for SFO-BHT $(12.37 \pm 0.26 \mathrm{meq} / \mathrm{kg}$ oil $)$ may be comparable to those recorded for SFO + 300 ppm CPSO (12.95 $\pm 0.17 \mathrm{meq} / \mathrm{kg}$ oil $)$ and SFO $+300 \mathrm{ppm} \mathrm{SPSO}$ (13.45 $\pm 0.32 \mathrm{meq} / \mathrm{kg}$ oil), suggesting that both CPSO and SPSO may provide oxidative stability to sunflower oil during heat treatment.

Table 4. Peroxide value of oil samples in response to heat treatment.

\begin{tabular}{cccc}
\hline \multirow{2}{*}{ Sample } & \multicolumn{3}{c}{ PV (meq/kg Oil) } \\
\cline { 2 - 4 } & Initial & $\mathbf{4} \mathbf{~ h}$ & $\mathbf{8 ~ h}$ \\
\hline SFO & $1.58 \pm 0.03^{\mathrm{a}}$ & $11.23 \pm 0.18^{\mathrm{a}}$ & $16.40 \pm 0.17^{\mathrm{a}}$ \\
SFO + BHT & $1.59 \pm 0.03^{\mathrm{a}}$ & $7.83 \pm 0.17^{\mathrm{b}}$ & $12.37 \pm 0.26^{\mathrm{b}}$ \\
CPSO & $0.52 \pm 0.01^{\mathrm{b}}$ & $3.63 \pm 0.16^{\mathrm{c}}$ & $4.88 \pm 0.10^{\mathrm{c}}$ \\
SPSO & $0.66 \pm 0.02^{\mathrm{b}}$ & $4.26 \pm 0.34^{\mathrm{c}}$ & $5.84 \pm 0.09^{\mathrm{c}}$ \\
SFO + 100 ppm CPSO & $1.48 \pm 0.03^{\mathrm{c}}$ & $10.62 \pm 0.14^{\mathrm{a}}$ & $15.55 \pm 0.14^{\mathrm{a}}$ \\
SFO + 200 ppm CPSO & $1.37 \pm 0.04^{\mathrm{d}}$ & $9.27 \pm 0.10^{\mathrm{d}}$ & $14.16 \pm 0.37^{\mathrm{d}, \mathrm{e}}$ \\
SFO + 300 ppm CPSO & $1.29 \pm 0.04^{\mathrm{e}}$ & $8.88 \pm 0.11^{\mathrm{d}, \mathrm{e}}$ & $12.95 \pm 0.17^{\mathrm{b}}$ \\
SFO + 100 ppm SPSO & $1.49 \pm 0.04^{\mathrm{c}}$ & $10.66 \pm 0.12^{\mathrm{a}}$ & $15.66 \pm 0.20^{\mathrm{a}}$ \\
SFO + 200 ppm SPSO & $1.40 \pm 0.03^{\mathrm{d}}$ & $9.72 \pm 0.12^{\mathrm{d}, \mathrm{f}}$ & $14.28 \pm 0.24^{\mathrm{d}}$ \\
SFO + 300 ppm SPSO & $1.30 \pm 0.02^{\mathrm{e}}$ & $9.44 \pm 0.22^{\mathrm{d}, \mathrm{f}}$ & $13.45 \pm 0.32^{\mathrm{b}, \mathrm{e}}$
\end{tabular}

The values are expressed as mean values \pm standard deviations of all measurements. ${ }^{\mathrm{a}-\mathrm{f}} \mathrm{A} t$-test was used to compare the mean differences registered among samples; data within the same column sharing different superscripts are significantly different $(p<0.05)$; data within the same column sharing the same superscripts are not significantly different $(p>0.05)$. 


\section{3. $p$-Anisidine Value ( $p$-AV)}

The data shown in Table 5 express the $p$-AV recorded during the heating process in response to the addition of BHT, CPSO and SPSO.

Table 5. The $p-\mathrm{AV}$ of oil samples in response to heat treatment.

\begin{tabular}{|c|c|c|c|}
\hline \multirow{2}{*}{ Sample } & \multicolumn{3}{|c|}{$p$-AV (ppm) } \\
\hline & Initial & $4 \mathrm{~h}$ & $8 \mathrm{~h}$ \\
\hline SFO & $1.873 \pm 0.025^{\mathrm{a}}$ & $52.119 \pm 1.372^{a}$ & $72.496 \pm 1.340^{a}$ \\
\hline $\mathrm{SFO}+200$ ppm BHT & $1.861 \pm 0.027^{\mathrm{a}}$ & $47.121 \pm 1.570^{b}$ & $65.397 \pm 1.800^{b}$ \\
\hline CPSO & $0.673 \pm 0.025^{b}$ & $32.549 \pm 0.938^{c}$ & $40.182 \pm 1.353^{c}$ \\
\hline SPSO & $0.723 \pm 0.023^{b}$ & $34.814 \pm 0.987^{\mathrm{d}}$ & $41.570 \pm 0.972^{\mathrm{c}}$ \\
\hline $\mathrm{SFO}+100 \mathrm{ppm}$ CPSO & $1.713 \pm 0.022^{c}$ & $50.666 \pm 1.568^{\mathrm{a}, \mathrm{f}}$ & $69.682 \pm 1.141^{d}$ \\
\hline $\mathrm{SFO}+200$ ppm CPSO & $1.664 \pm 0.040^{c}$ & $48.5295 \pm 1.016^{\mathrm{b}, \mathrm{g}}$ & $66.553 \pm 1.408^{b, f}$ \\
\hline $\mathrm{SFO}+300$ ppm CPSO & $1.488 \pm 0.028^{\mathrm{d}}$ & $45.9195 \pm 1.234^{\mathrm{b}, \mathrm{h}}$ & $63.445 \pm 1.259^{b, g}$ \\
\hline SFO + 100 ppm SPSO & $1.846 \pm 0.032^{\mathrm{a}}$ & $51.3525 \pm 1.592^{\mathrm{a}, \mathrm{i}}$ & $70.227 \pm 0.932 \mathrm{~d}$ \\
\hline $\mathrm{SFO}+200 \mathrm{ppm}$ SPSO & $1.769 \pm 0.047^{c}$ & $49.444 \pm 1.083^{\mathrm{e}, \mathrm{f}, \mathrm{g}, \mathrm{i}}$ & $67.818 \pm 1.175^{b, f}$ \\
\hline $\mathrm{SFO}+300$ ppm SPSO & $1.687 \pm 0.023^{c}$ & $46.298 \pm 1.638^{\mathrm{b}, \mathrm{h}}$ & $64.122 \pm 1.208^{b, g}$ \\
\hline
\end{tabular}

The values are expressed as mean values \pm standard deviations of all measurements. ${ }^{\mathrm{a}-\mathrm{i}} \mathrm{A} t$-test was used to compare the means differences registered among samples; data within the same column sharing different superscripts are significantly different $(p<0.05)$; data within the same column sharing the same superscripts are not significantly different $(p>0.05)$.

Analyzing the results obtained for the samples of sunflower oil with BHT and different doses of CPSO and SPSO added, it can be seen that, with the increase of the heat treatment duration, the $p-\mathrm{AV}$ value also increases $(p<0.05)$ (Table 5). This increase in $p-\mathrm{AV}$ is attributed to the formation of secondary oxidation products.

After $4 \mathrm{~h}$ of heat treatment, the increase in $p-\mathrm{AV}$ was very fast in all samples and continued to increase with the heat treatment period, but at a slower rate.

The $p$-AV value ranged from $0.673-70.222 \mathrm{ppm}$ in the oil samples with the addition of CPSO and SPSO and 1.861-165.397 ppm in the SFO + BHT samples, while for the control sample (SFO), values between 1.873-65.397 ppm were recorded.

Both after $4 \mathrm{~h}$ and after $8 \mathrm{~h}$ of heat treatment, the highest $p-\mathrm{AV}$ was observed for the control sample (SFO), followed by SFO + 100 ppm SPSO, SFO + 100 ppm CPSO, $\mathrm{SFO}+200 \mathrm{ppm} \mathrm{SPSO}, \mathrm{SFO}+200 \mathrm{ppm} \mathrm{CPSO}, \mathrm{SFO}+300 \mathrm{ppm} \mathrm{SPSO}, \mathrm{SFO}+300 \mathrm{ppm} \mathrm{CPSO}$ and SFO-BHT, respectively. CPSO and SPSO samples recorded the lowest $p$-AV values both before and after heat treatment.

\subsection{Total Oxidation Value (TOTOX Value)}

The TOTOX values for the analyzed oil samples increased significantly with the heating time (Figure 2).

The TOTOX values for the samples mixed with BHT, CPSO and SPSO were significantly lower than the values recorded for the control sample.

After $4 \mathrm{~h}$ of convective heating, the addition of oil with different doses of CPSO and SPSO led to a decrease in the TOTOX value in the range of 65.178-72.673 compared to the control (74.579), while the sample supplemented with BHT recorded a value of 43.334 .

Heating for $8 \mathrm{~h}$ decreased the TOTOX value to $90.934-101.366$ compared to 105.347 for the control, while the sample supplemented with BHT recorded a value of 53.358. The best inhibitory effect against oil oxidation during heating was recorded in the $\mathrm{SFO}+300 \mathrm{ppm}$ CPSO test. In both stages of the heat treatment, the lowest TOTOX values were recorded when supplementing the sunflower oil with $300 \mathrm{ppm}$ CPSO and SPSO, with these concentrations approaching the level of inhibition recorded when using BHT. 


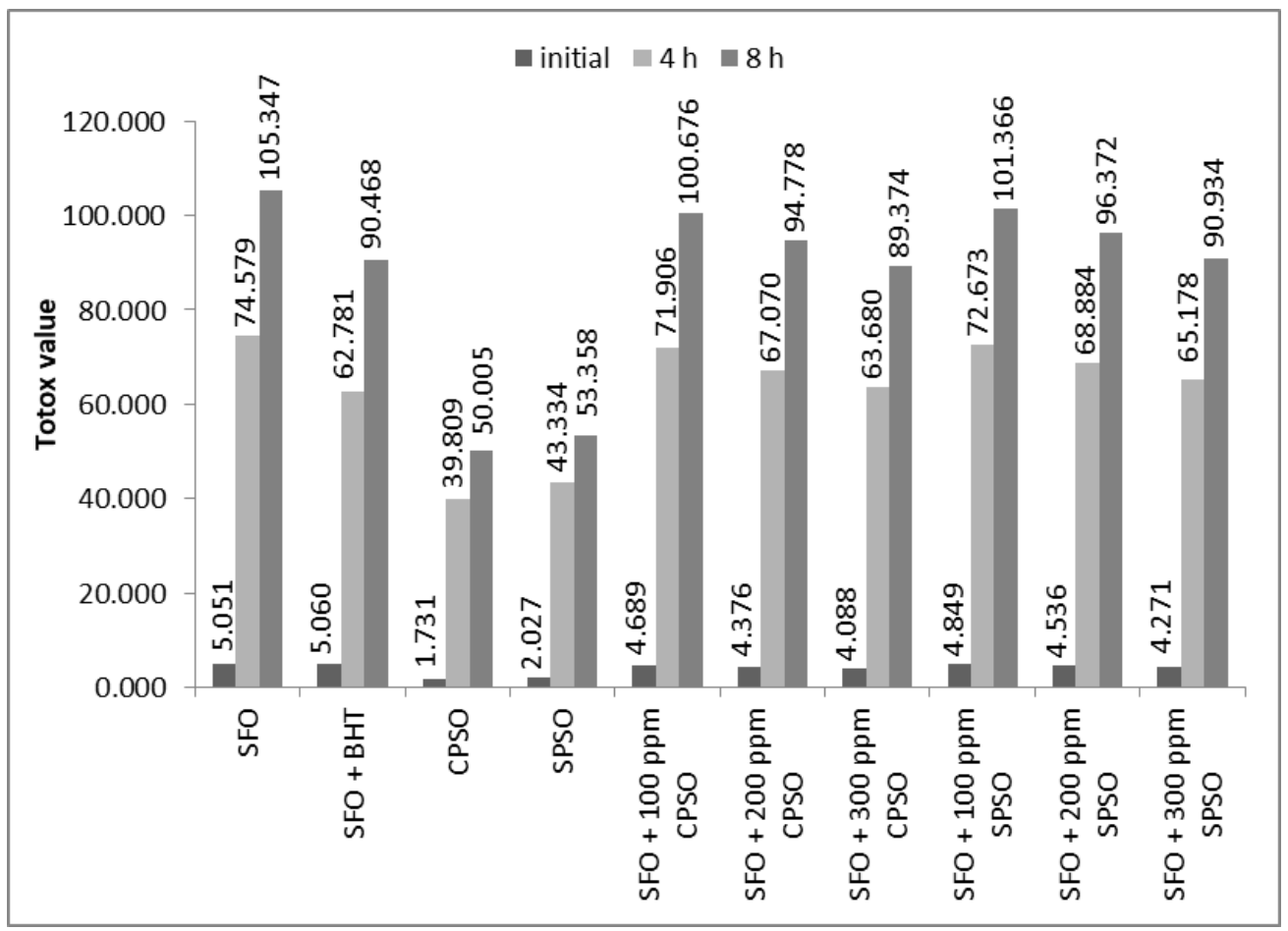

Figure 2. The impact of CPSO, SPSO and BHT on TOTOX value during heating of sunflower oil.

\subsection{Assessing the Lipid Oxidation Degree of Oil Samples by TBA Test}

The data presented in the Table 6 represent changes in the TBA value content during the heating process as a result of BHT, CPSO and SPSO supplementation $(p<0.05)$.

In all samples a progressive increase of TBA value is observed during the heat treatment period. In the case of the control sample, the increase was the most significant, almost up to 10 times higher at the end of the thermal process compared to the initial value. The smallest increase was recorded for CPSO and SPSO, with the final value of TBA being up to 5 times higher than the original one.

The TBA values recorded for CPSO and SPSO were significantly lower than for SFO both before and after the heat treatment, due to the fact that the number of polyunsaturated fatty acids decreased less in the case of CPSO and SPSO than in the case of SFOs.

After the application of thermal treatment for $4 \mathrm{~h}$ and $8 \mathrm{~h}$, the TBA values in the SFO with addition of CPSO and SPSO were significantly lower compared to the control sample, with the best results being recorded in the case of the SFO + 300 ppm CPSO sample, which is even smaller than in the case of the SFO sample with a synthetic antioxidant.

CPSO and SPSO at a 200 ppm use a rate of lipid oxidation inhibition in a similar manner to the synthetic antioxidant.

In the case of the samples in the form of SFO and CPSO or SPSO mixtures, the TBA value was dependent to the dose; therefore, the lipid oxidation degree was inversely proportional to the percentage of the CPSO and the SPSO added. Thus, the lowest TBA values were obtained for SFO +300 ppm CPSO and SFO + 300 ppm SPSO, and the highest for SFO + 100 ppm CPSO and SFO + 100 ppm SPSO, for both 4 and $8 \mathrm{~h}$. Moreover, good results were recorded in samples of SFO with the addition of CPSO compared with those with SPSO.

Thus, the results obtained in the present study suggest that the lipid oxidation process occurring during heat treatment can be reduced by the addition of CPSO and SPSO, and as such may be used as potential natural antioxidants in order to improve the oxidative stability of SFO during heat treatment. 
Table 6. Changes in TBA value of oil samples in response to heat treatment.

\begin{tabular}{|c|c|c|c|}
\hline \multirow{2}{*}{ Sample } & \multicolumn{3}{|c|}{ TBA ( $\mu$ g MDA/g) } \\
\hline & Initial & $4 \mathrm{~h}$ & $8 \mathrm{~h}$ \\
\hline SFO & $20.26 \pm 0.5^{\mathrm{a}}$ & $143.56 \pm 4.23^{\mathrm{a}}$ & $180.08 \pm 5.82^{a}$ \\
\hline $\mathrm{SFO}+\mathrm{BHT}$ & $20.22 \pm 0.47^{\mathrm{a}}$ & $98.13 \pm 2.87^{b}$ & $125.43 \pm 3.91^{b}$ \\
\hline CPSO & $9.24 \pm 0.32^{b}$ & $28.65 \pm 0.89^{c}$ & $53.19 \pm 1.88^{c}$ \\
\hline SPSO & $13.30 \pm 0.37^{c}$ & $39.05 \pm 1.07^{\mathrm{d}}$ & $70.52 \pm 2.24^{\mathrm{d}}$ \\
\hline $\mathrm{SFO}+100 \mathrm{ppm}$ CPSO & $18.70 \pm 0.51^{\mathrm{d}}$ & $123.25 \pm 3.24^{\mathrm{e}}$ & $146.30 \pm 4.11^{\mathrm{e}}$ \\
\hline $\mathrm{SFO}+200 \mathrm{ppm}$ CPSO & $17.73 \pm 0.42^{\mathrm{e}, \mathrm{g}}$ & $100.61 \pm 3.02^{b}$ & $125.92 \pm 3.10^{b}$ \\
\hline $\mathrm{SFO}+300 \mathrm{ppm}$ CPSO & $16.59 \pm 0.40^{\mathrm{f}}$ & $85.51 \pm 2.66^{\mathrm{f}}$ & $98.92 \pm 2.49^{\mathrm{e}}$ \\
\hline $\mathrm{SFO}+100$ ppm SPSO & $19.42 \pm 0.46^{\mathrm{d}, \mathrm{h}}$ & $131.19 \pm 4.47^{\mathrm{f}}$ & $164.77 \pm 5.19^{f}$ \\
\hline $\mathrm{SFO}+200 \mathrm{ppm}$ SPSO & $18.58 \pm 0.47^{\mathrm{d}}$ & $112.81 \pm 3.47^{\mathrm{g}}$ & $139.51 \pm 4.19^{g}$ \\
\hline $\mathrm{SFO}+300 \mathrm{ppm}$ SPSO & $17.91 \pm 0.41^{\mathrm{d}, \mathrm{g}}$ & $96.46 \pm 2.96^{b}$ & $114.24 \pm 3.51^{\mathrm{h}}$ \\
\hline
\end{tabular}

The values are expressed as mean values \pm standard deviations of all measurements. ${ }^{\mathrm{a}-\mathrm{h}} \mathrm{A}$ t-test was used to compare the means differences registered among samples; data within the same column sharing different superscripts are significantly different $(p<0.05)$; data within the same column sharing the same superscripts are not significantly different $(p>0.05)$.

\section{Discussion}

Increased consumption of edible oils worldwide is limited by several factors, including the content of trans fatty acids and rancid properties. Edible oils are highly susceptible to lipid oxidation and the loss of flavor that occurs during the frying process, depending on the fatty acid composition, shelf life and processing temperature [5]. It also affects numerous interactions between food constituents, which lead to both desirable and unwanted products.

The fatty acid composition of the SFO, SPSO and CPSO analyzed in this study is consistent with data reported in the literature [12,24,25]. Jarret et al. [26] obtained for CPSO the following values: $13.38 \%$ (C16:0), 3.61\% (C18:0), 6.55\% (C18:1), 76.1\% (C18:2), and for SPSO: $13.85 \%$ (C16.0), 3.23\% (C18:0), 7.51\% (C18:1) and 73.92\% (C18:2).

Silva et al. [27] reported a higher content of palmitic acid (23.16\%) and stearic acid $(18.25 \%)$, and lower for oleic acid (2.66\%) and linoleic (38.31\%), for sweet pepper oil.

The results obtained after the thermal treatment are consistent with other studies. Thus, Aladedunye and Przybylski [24] analyzed sunflower oil samples supplemented with different levels of linoleic acid subjected to heating at $140{ }^{\circ} \mathrm{C}$ for 14 days. The obtained results highlighted a decrease of PUFA content and an increase of SFA proportional with the duration of the heat treatment, in accord with the data reported in our study.

Medina-Juárez and Gámez-Meza [28] have found a decrease in PUFA content and an increase in SFA content after keeping sunflower oil at a frying temperature for $80 \mathrm{~h}$. Budryn et al. [12] have noticed a decrease of PUFA content and an increase of SFA content in a sunflower oil sample with the addition of green coffee extract exposed to heating at 110 and $180{ }^{\circ} \mathrm{C}$ for $60 \mathrm{~min}$, and further stored for 3 months. PV and $p$-AV together provide a complete overview of the oil oxidation process. PV is the measure of primary oxidation degree of oils and fats. The determination of peroxides can be used as an oxidation index for the early stages of lipid oxidation. The $p-\mathrm{AV}$ is a measure of the secondary oxidation of oils and fats [1]. A continuous increase of PV with heating time was observed for all the samples $(p<0.05)$. This increase is attributed to the formation of hydroperoxides, i.e., primary oxidation products. After $4 \mathrm{~h}$ of heat treatment, the PV increases very fast in all the analyzed samples, while between $4-8 \mathrm{~h}$ a slower rate was recorded.

The PV values recorded in our study for the samples of oil with the addition of CPSO and SPSO was in the range between $1.29-5.66 \mathrm{meq} / \mathrm{kg}$ oil.

Previous results highlighted the effect of byproducts enriched in antioxidant compounds on oil stability. Iqbal et al. [4] studied the antioxidant effect of pomegranate peel extract in the stabilization of sunflower oil, with the values obtained for the PV being between the range of 64.21-147.34 meq $/ \mathrm{kg}$ depending on the concentration of pomegranate peel extract used. Singh et al. [20] studied the antioxidant potential of Foeniculum vulgare 
volatile oil on sunflower oil and found that it is significantly more effective than butylated hydroxy toluene. Poiană [1] investigated the effectiveness of grape seed extract compared to butylated hydroxy toluene on retarding the lipid oxidation of sunflower oil subjected to convection heating up to $240 \mathrm{~min}$ under simulated frying conditions, with the values recorded being between $1.77-9.81 \mathrm{meq} / \mathrm{kg}$ oil, which are values comparable to those obtained in the present study.

In our study, the sample of oil with the addition of CPSO and SPSO registered values between 1.713-64.122 ppm. The results obtained in this study regarding the antioxidant effects of pepper seed oil and its role in stabilizing the thermo-oxidative effect of sunflower oil are in line with those reported in the literature. The effectiveness of grape seed extract compared to butylated hydroxytoluene on the delayed lipid oxidation of sunflower oil subjected to heating under simulated frying was studied by Poiana [1], who showed that after convective heating, the $p$-AV of the samples with the addition of grape seed extract records a decrease in the $p$ - $\mathrm{AV}$ depending on the dose; thus, $45.25 \mathrm{ppm}$ for a concentration of $200 \mathrm{ppm}$ grape seed extract to $35.75 \mathrm{ppm}$ for $1000 \mathrm{ppm}$ grape seed extract. Moreover, the effectiveness of blueberry processing byproducts compared to butylated hydroxy toluene on retarding the lipid oxidation of sunflower oil subjected to convection heating up to 240 min under simulated frying conditions was reported [29], with the $p$-AV value in this case also being dependent on the dose of blueberry byproduct extracts added (63.67 ppm for $200 \mathrm{ppm}$ blueberry byproduct extracts and $57.81 \mathrm{ppm}$ for $800 \mathrm{ppm}$ blueberry byproduct extracts). Other studies have reported the antioxidant effect of spearmint or pomegranate essential oils in the stabilization of sunflower oil [30]. The TOTOX value is a mathematical prediction of oxidative stability and is used as an indicator of the overall oxidative stability being correlated with the degree of oil damage [1]. The values of TOTOX recorded in our study (between 4.088-101.366) for all the samples are comparable to those reported in other studies. Poiana [1] obtained, for samples of oil supplemented with grape seed oil, TOTOX values in the range of 5.82-92.27, while Ungureanu et al. [29] concluded that the addition of other oils or extracts with a high antioxidant activity may limit or reduce the lipid oxidation of sunflower oil during heating. The values reported by Ungureanu et al. [29] were between the range 51.19-81.27 for the sample supplemented with blueberry byproduct extracts, which are values comparable to those obtained in the present study. The oxidation degree of the vegetable oils subjected to thermal treatment was evaluated on the basis of the thiobarbituric acid test (TBA). The malondialdehyde amount generated in response to the oxidation processes undergoing in the oil samples has been quantified on the basis of the calibration curve. The thiobarbituric acid test gives satisfactory results, with the amount of malondialdehyde formed increasing with the evolution of the oxidation process. After the tests were carried out, an increase of malondialdehyde content was found due to oxidation which occurred after the heat treatment.

In our study, the TBA value varied from 18.70-114.24 $\mu \mathrm{gMDA} / \mathrm{mL}$ oil. Similar observations were also reported by Yang et al. [5], who studied the thermal oxidative stability of red pepper seed oil in which different proportions of capsaicin or tocopherol were added as antioxidants during heating up to $140 \pm 5{ }^{\circ} \mathrm{C}$ for $48 \mathrm{~h}$. Similar results were also reported by Iqbal et al. [4], who studied the antioxidant effect of pomegranate peel extract in the stabilization of sunflower oil, and observed that pomegranate peel extract at concentrations of 800-850 ppm has a stabilization efficiency comparable to conventional synthetic antioxidants, i.e., butylated hydroxy toluene at its legal limit. Moreover, Ungureanu et al. [29] investigated the effectiveness of blueberry byproduct extracts compared to butylated hydroxy toluene on retarding the lipid oxidation of sunflower oil subjected to convection heating up to $240 \mathrm{~min}$ under simulated frying conditions, obtaining values between 5.16-51.58 $\mu \mathrm{g}$ MDA/mL oil, which are values comparable to those obtained in the present study.

Wang et al. [31] studied the influence of spearmint essential oil on sunflower oil during deep frying, demonstrating the antioxidant effect of M. spicata in sunflower oil. 
Moreover, Hussain [32] studied the efficacy of sesame seed extracts in stabilizing the sunflower oil during storage, finding that it can be considered a very good choice as a natural antioxidant to stabilize the sunflower oil.

\section{Conclusions}

From the present study, we can conclude that chili pepper seed oil and sweet pepper seed oil can stabilize sunflower oil effectively at all the concentrations tested. Chili pepper seed oil and sweet pepper seed oil at concentrations of $300 \mathrm{ppm}$ have better stabilization efficiency compared to conventional synthetic antioxidants, i.e., BHT at its legal limit, and improves the resistance of sunflower oil against thermal deteriorative changes. Besides this, the polyunsaturated fatty acid content is increased appreciably by creating resistance in the oil against oxidative rancidity. Therefore, through this study, chili pepper seed oils and sweet pepper seed oils can be recommended as a potent source of antioxidants for the stabilization of sunflower oils.

Author Contributions: Conceptualization, I.C., M.N., E.A. and M.-A.P.; methodology, I.C., M.N., A.C., M.-A.P., C.D., I.P., A.I.C., D.O. and I.R.; writing-original draft preparation, I.C., M.N., E.A., M.-A.P. and D.R.; writing - review and editing, I.C., M.N., E.A., M.-A.P., D.R. and C.D.; visualization, I.C., M.N., A.C., E.A., M.-A.P., D.R., C.D., I.P., A.I.C., D.O. and I.R.; supervision, I.C., E.A. and I.R.; funding acquisition, I.R. All authors have read and agreed to the published version of the manuscript.

Funding: This paper is published from the own funds of the Banat's University of Agricultural Sciences and Veterinary Medicine "King Michael I of Romania" from Timisoara, Romania.

Institutional Review Board Statement: Not applicable.

Informed Consent Statement: Not applicable.

Data Availability Statement: The report of the analyses performed for the samples in the paper can be found at the Interdisciplinary Research Platform (PCI) belonging to the Banat University of Agricultural Sciences and Veterinary Medicine "King Michael I of Romania" from Timisoara, being registered with number 21c/17.01.2018.

Acknowledgments: We have been able to carry out this research with the support of the Interdisciplinary Research Platform belonging to the Banat University of Agricultural Sciences and Veterinary Medicine "King Michael I of Romania" from Timisoara, where the analysis were made.

Conflicts of Interest: The authors declare no conflict of interest.

\section{References}

1. Poiană, M.A. Enhancing Oxidative Stability of Sunflower Oil during Convective and Microwave Heating Using Grape Seed Extract. Int. J. Mol. Sci. 2012, 13, 9240-9259. [CrossRef] [PubMed]

2. Wąsowicz, E.; Gramza, A.; Hęś, M.; Jeleń, H.H.; Korczak, J.; Małecka, M.; Mildner-Szkudlarz, S.; Rudzińska, M.; Samotyja, U.; Zawirska-Wojtasiak, R. Oxidation of Lipids in Food. Pol. J. Food Nutr. Sci. 2004, 13, 87-100.

3. Tena, N.; Lobo-Prieto, A.; Aparicio, R.; García-González, D.L. Storage and Preservation of Fats and Oils. Encycl. Food Secur. Sustain. 2019, 2, 605-618.

4. Iqbal, S.; Haleem, S.; Akhtar, M.; Zia-ul-Haq, M.; Akbar, J. Efficiency of Pomegranate Peel Extracts in Stabilization of Sunflower Oil under Accelerated Conditions. Food Res. Int. 2008, 41, 194-200. [CrossRef]

5. Yang, C.Y.; Mandal, P.K.; Han, K.H.; Fukushima, M.; Choi, K.; Kim, C.J.; Lee, C.H. Capsaicin and Tocopherol in Red Pepper Seed Oil Enhances the Thermal Oxidative Stability during Frying. J. Food Sci. Technol. 2010, 47, 162-165. [CrossRef] [PubMed]

6. Laguerre, M.; Lecomte, J.; Villeneuve, P. Evaluation of the Ability of Antioxidants to Counteract Lipid Oxidation: Existing Methods, New Trends and Challenges. Prog. Lipid Res. 2007, 46, 244-282. [CrossRef]

7. Yanishlieva, N.V.; Marinova, E.M. Stabilization of Edible Oils with Natural Antioxidants. Eur. J. Lipid Sci. Technol. 2001, 103, 752-767. [CrossRef]

8. Zhang, Y.; Yang, L.; Zu, Y.; Chen, X.; Wang, F.; Liu, F. Oxidative Stability of Sunflower Oil by Carnosic Acid Compared with Synthetic Antioxidants during Accelerated Storage. Food Chem. 2010, 118, 656-662. [CrossRef]

9. Kalantzakis, G.; Blekas, G. Effect of Greek Sage and Summer Savory Extracts on Vegetable Oil Thermal Stability. Eur. J. Lipid Sci. Technol. 2006, 108, 842-847. [CrossRef]

10. Wang, L.; Liu, H.-M.; Qin, G.-Y. Structure Characterization and Antioxidant Activity of Polysaccharides from Chinese Quince Seed Meal. Food Chem. 2017, 234, 314-322. [CrossRef] [PubMed] 
11. Blasi, F.; Rocchetti, G.; Montesano, D.; Lucini, L.; Chiodelli, G.; Ghisoni, S. Changes in Extra-Virgin Olive Oil Added with LYCIUM Barbarum L. Carotenoids during Frying: Chemical Analyses and Metabolomic Approach. Food Res. Int. 2018, 105, 507-516. [CrossRef]

12. Budryn, G.; Nebesny, E.; Zyzelewicz, D.; Oracz, J. Properties of Model Systems of Sunflower Oil and Green Coffee Extract after Heat Treatment and Storage. LWT-Food Sci. Technol. 2014, 59, 467-478. [CrossRef]

13. Alama, M.A.; Syazwaniea, N.F.; Mahmoda, N.H.; Badaluddina, N.A.; Mustafab, K.A.; Aliasa, N.; Aslanic, F.M.; Prodhand, A. Evaluation of Antioxidant Compounds, Antioxidant Activities and Capsaicinoid Compounds of Chili (Capsicum sp.) Germplasms Available in Malaysia. J. Appl. Res. Med. Aromat. Plants 2018, 9, 46-54. [CrossRef]

14. Kogure, K.; Goto, S.; Nishimura, M.; Yasumoto, M.; Abe, K.; Ohiwa, C.; Sassa, H.; Kusumi, T.; Terrada, H. Mechanism of Potent Antiperoxidative Effect of Capsaicin. Biochim. Biophys. Acta 2002, 1573, 84-92. [CrossRef]

15. Lee, C.H.; Lee, I.H. The Effect of Capsaicin on the Thermal and Oxidative Stability of Soybean Oil. Anim. Resour. Res. 2001, $22,9-17$.

16. Lee, C.H.; Han, K.H.; Kim, A.Y.; Lee, S.K.; Hong, G.E.; Pyun, C.W.; Choi, K.D.; Yang, C.Y. Effect of Hot Pepper Seed Oil, Capsaicin and Alpha-Tocopherol on Thermal Oxidative Stability in Lard and Soy Bean Oil. Korean J. Food Sci. Anim. Resourc. 2008, 28, 660-666. [CrossRef]

17. Iordănescu, O.A.; Radulov, I.P.; Buhan, I.; Cocan, I.; Berbecea, A.A.; Popescu, I.; Poșta, D.S.; Camen, D.; Lalescu, D. Physical, Nutritional and Functional Properties of Walnuts Genotypes (Juglans regia L.) from Romania. Agronomy 2021, 11, 1092. [CrossRef]

18. Association of Coaching Supervisors. Official and Recommended Practices of the American Oil Chemists' Society, Official Methods and Recommended Practices, 5th ed.; Firestone, D., Ed.; AOAC Press: Champaign, IL, USA, 1998.

19. AOCS. Official Method Cd 18-90, p-Anisidine Value, Official Methods and Recommended Practices of the AOCS; AOCS: Urbana, IL, USA, 2017.

20. Gordon, M.H. Measuring Antioxidant Activity, Ch 4. In Antioxidants in Food: Practical Applications; Pokorny, J., Yanishlieva, N., Gordon, M., Eds.; CRC Press: Boca Raton, FL, USA, 2001; pp. 71-80.

21. Singh, G.; Maurya, S.; de Lampasona, M.P.; Catalan, C. Chemical Constituents, Antifungal and Antioxidative Potential of Foeniculum Vulgare Volatile Oil and Its Acetone Extract. Food Control 2006, 17, 745-752. [CrossRef]

22. Kikuzaki, H.; Nakatani, N. Antioxidant Effect of Some Ginger Constituents. J. Food Sci. 1993, 58, 1407-1410. [CrossRef]

23. Tarladgis, B.G.; Watts, B.M.; Younathan, M.T.; Dugan, L. A Distillation Method for the Quantitative Determination of Malonaldehyde in Rancid Food. J. Am. Oil Chem. Soc. 1960, 37, 44-48. [CrossRef]

24. Aladedunye, F.; Przybylski, R. Frying Stability of High Oleic Sunflower Oils as Affected by Composition of Tocopherol Isomers and Linoleic Acid Content. Food Chem. 2013, 141, 2373-2378. [CrossRef]

25. Alexa, E.; Poiană, M.A.; Peev, C.; Dehelean, C. Detection of Vegetable Oils Adulteration on the Basis of Fatty Acids Composition Determined by RP-HPLC. Rev. De Chim. 2006, 57, 285-289.

26. Jarret, R.L.; Levy, I.J.; Potter, T.L.; Cermak, S.C. Seed Oil and Fatty Acid Composition in Capsicum spp. J. Food Compos. Anal. 2013, 30, 102-108. [CrossRef]

27. Silva, L.R.; Azevedo, J.; Pereira, M.J.; Valentão, P.; Andrade, P.B. Chemical Assessment and Antioxidant Capacity of Pepper (Capsicum annuum L.) Seeds. Food Chem. Toxicol. 2013, 53, 240-248. [CrossRef] [PubMed]

28. Medina-Juárez, L.Á.; Gámez-Meza, N. Effect of Refining Process and Use of Natural Antioxidants on Soybean Oil. In SoybeanBiochemistry, Chemistry and Physiology; Ng, T.-B., Ed.; Books on Demand: Norderstedt, Germany, 2011; pp. 435-454.

29. Ungureanu, C.-R.; Poiana, M.-A.; Cocan, I.; Lupitu, A.I.; Alexa, E.; Moigradean, D. Strategies to Improve the Thermo-Oxidative Stability of Sunflower Oil by Exploiting the Antioxidant Potential of Blueberries Processing Byproducts. Molecules 2020, $25,5688$. [CrossRef] [PubMed]

30. Wang, D.; Meng, Y.; Zhao, X.; Fan, W.; Yi, T.; Wang, X. Sunflower Oil Flavored by Essential Oil from Punica Granatum Cv. Heyinshiliu Peels Improved Its Oxidative Stability and Sensory Properties. LWT 2019, 111, 55-61. [CrossRef]

31. Wang, D.; Chen, X.; Wang, Q.; Meng, Y.; Wang, D.; Wang, X. Influence of the Essential Oil of Mentha Spicata Cv. Henanshixiang on Sunflower Oil during the Deep-Frying of Chinese Maye. LWT 2020, 122, 109020. [CrossRef]

32. Hussain, S.A.; Hameed, A.; Ajmal, I.; Nosheen, S.; Suleriam, H.A.R.; Song, Y. Effects of Sesame Seed Extract as a Natural Antioxidant on the Oxidative Stability of Sunflower Oil. J. Food Sci. Technol. 2018, 55, 4099-4110. [CrossRef] 